\title{
História do Design na disciplina de "Fundamentos do Design": experiência, hábito e projeto no ensino e na interpretação da história
}

José Neto de Faria - josenetodesigner@yahoo.com.br

Universidade Anhembi Morumbi - Design Digital - Design Gráfico com ênfase em Tipografia - Fundamentos do Design $\mid 1^{\circ}$ semestre

Palavras-chave: História do Design; Experiência; Hábito; Projeto; Ensino e Interpretação.

\section{"FUNDAMENTOS DO DESIGN".}

Este texto propõe refletir sobre a proposta didático pedagógica de ensino da "História do Design" implantada na disciplina de "Fundamentos do Design". A disciplina faz parte do conjunto de cadeiras responsáveis pelo desenvolvimento dos conteúdos de história, teoria e crítica do design, dos cursos de Design Digital e Design Gráfico, da Universidade Anhembi Morumbi: "Fundamentos do Design" com 80h; "História da Arte e do Design" com 80h; e, dependendo do curso, "Laboratório de Arte e Design Digital” ou "Laboratório de Arte e Design Gráfico" com 40h. Foi baseada nos estudos sobre as relações entre experiência, arte e educação, de John Dewey (2010; 2011), os processos de individuação e formação do conhecimento, de Gilbert Simondon (2009), e as relações dos modos de pensar com a história do design, de Rosalía Torrent e Joan M. Marín (2005).

A disciplina de "Fundamentos do Design", tanto no curso de Design Digital quanto no de Design Gráfico, conduz a prática projetual e faz parte de um conjunto de disciplinas, "Linguagem Visual”, "Imagem Gráfica e Digital” e "Comunicação e Expressão”, as quais articuladas devem promover a conexão de um conjunto de conhecimentos, que passam, na visão dos discentes, objetivamente a contribuir e a fazer parte da fundamentação teórica

Faria, José Neto de. “História do Design na disciplina de 'Fundamentos do Design': experiência, hábito e projeto no ensino e na interpretação da história", in Anais do 1o Seminário Paulista do ensino da história do design 2014 [= Blucher Design Proceedings, num.3, vol. 1]. São Paulo: Blucher, 2014. ISSN 23-18-6968 http://dx.doi.org/10.5151/designpro-spehd-11 
de qualquer projeto de design. Assim, os discentes percebem que o conhecimento teórico, crítico e histórico não serve somente para a construção de um posicionamento retórico, mas para fundamentar as ações que transformam o mundo.

\section{EXPERIÊNCIA, HÁBITO E CONHECIMENTO.}

Assim, no processo de ensino da história do design, a experiência é vista como o elemento base da individuação, da constituição de novos conhecimentos, depende de três princípios, do hábito, da continuidade e da interação, para promover o contínuo aprendizado no processo de educação e formação do indivíduo. Segundo Dewey (2011, p.37-43) a educação pela experiência cria a possibilidade da escolha, ou da definição de uma "direção", a qual passa pela capacidade do educando ou do educador de promover o "despertar e o enfrentamento de desafios" em detrimento de "indulgências excessivas". As experiências internas (objetivos e estados internos do indivíduo) e as experiências externas (objetivos e estados externos do mundo das coisas), em interação e choque no indivíduo, definem a direção que irá tomar, bem como os hábitos que serão formados. As condições internas do indivíduo em contato com as condições objetivas impostas pelo lado externo estabelecem, num momento de consciência da mente e do próprio corpo, os quais participam ativamente do dinamismo do processo de individuação, o confronto, a interpretação e a narração das estruturas que eclodem do sistema.

\section{FOCO DA DISCIPLINA.}

A disciplina "Fundamentos do Design" tem como foco a história da arte e do design, periférico latino americano (Argentina, Brasil, Chile, Colômbia, Peru, México e Venezuela) e central internacional (Europa e América do Norte), privilegia um recorte temporal entre 1780 e 1990, que seleciona algumas correntes artísticas e as principais experiências de ensino das artes aplicadas e/ou do design. Contempla cinco modelos de ensino internacionais e os seus reflexos e dicotomias no sistema de ensino brasileiro: dos Liceus de Artes e Ofícios, École Nationale Supérieure d'Arts et Métiers - 1780; das Escolas do Governo, Government School of Design - 1837; das Escolas da Reconstrução, Staatliche Bauhaus - 1919 e Bxytemác - 1920; das Escolas Razão e da Ciência, Hochschule für Gestaltung Ulm - 1953; e das Escolas do Indivíduo Psíquico, Cranbrook Academy of Art 1984. 


\section{DESIGN, SOCIEDADE, PROJETO E FUTURO.}

O começo proposital, do estudo da história do design pelas escolas de design, tem o intuito gerar a discussão e compreensão de que o discente ao conhecer a história, ao olhar para o passado, pode também olhar para o futuro, e idealizar e propor a construção no presente, com a ação de suas próprias mãos, do que será o seu legítimo futuro. A intensão principal é promover a reflexão sobre as correntes artísticas e os modelos de ensino de design de cada período, a fim de que os discentes possam analisar criticamente o modelo o qual vivenciam, ponderar e propor uma abordagem projetual condizente com o futuro que desejam. Visto que, já em 1851, Manuel de Araújo Porto-Alegre (2014) afirmava:

(...) o artista é sempre um espelho fidedigno do estado de espírito da sociedade, e que a matéria, que é modificada ou transfusada pela mão da indústria, é um eixo que acompanha o caráter do século (...). O maior engenheiro, uma dessas almas, como a de Leonardo da Vinci, ou Michelangelo, nada faria no Brasil, porque as belas-artes ainda não fazem parte da nossa vida social, quer no culto nacional, quer nas recompensas à virtude e ao heroísmo: ainda não temos esse amor do belo, que tanto distingue as raças que tomaram a dianteira na civilização moderna. (PORTO-ALEGRE, 1851 apud KOVENSKY; SQUEFF, 2014, pg. 295-307).

O namoro da história, revisita modelos não para que sejam copiados mas para que a sociedade numa reflexão sobre causas e consequências, exercite a crítica necessária a proposição dos seus próprios modelos de desenvolvimento da economia, da indústria e do design. Logo, o "esforço contra a hegemonia tecnológica, que sucede no ocidente, e o "complexo de inferioridade tecnológica" no campo das artes, esbarram na estrutura de um sistema: o problema é fundamentalmente político-econômico" (BARDI, 1994, pg. 13).

A vontade, movida pelas experiências e a formação dos hábitos, define os valores que serão compartilhados por uma determinada sociedade, e consequentemente, prescreve as tenções e as distensões que poderão ser capazes de promover para estabelecerem o futuro almejado. Assim, Porto-Alegre (2014) destaca no desenho de cada objeto da cultura material, um relato do estado de desenvolvimento sociocultural de cada nação.

Estuda-se o desenho convenientemente, que a arte do ourives ressurgirá do seu estado de abatimento entre os nacionais, e alcançará aquele grau de perfeição que se denota nos produtos que nos vêm cotidianamente da Europa (...) o desenho, em todas as obras de arte, é sempre o espelho que reflete o estado de civilização de um povo, e o que 
indica a sua infância, os seus progressos e a sua decadência. (PORTO-ALEGRE, 1851 apud KOVENSKY; SQUEFF, 2014, pg. 298).

Contudo, os discentes ainda devêm considerar o modo como a sociedade organiza a sua vida social, o seu sistema de ensino e seus setores produtivos, a fim de observar como os modos de pensar de cada setor introduzem certas ingerências que caracterizam o contemporâneo. Deste modo, John Dewey (2011) questionou a qualidade da relação indústria e escola nos anos 1930:

(...) o problema da relação entre a indústria e a educação era formulada da seguinte maneira: O que a escola fará pela indústria? Mas hoje a pergunta deve ser formulada exatamente ao contrário: $O$ que a indústria pode fazer pela escola? Ou melhor: O que ela pode fazer com a escola? (DEWEY, 2011, pg. 23).

\section{ANÁLISE CRÍTICA, PROPOSIÇÃO E IMPLANTAÇÃO.}

A disciplina foi preparada para ser ministrada, em cada aula, com três momentos. 0 momento introdutório de contextualização e montagem do cenário que propiciou o acúmulo de certas ideias, propriedades e características; o momento de análise e reflexão crítica das relações existentes, entre o momento histórico e os artefatos culturais gerados por ativos, artesãos, artistas e designers, considerados relevantes no design; e por fim, o momento de proposição da leitura e interpretação dos valores estéticos, socioculturais e tecnológicos da cadeia e a tradução em uma peça com a qual possa se analisar o domínio sobre a linguagem. As cadeias de acontecimentos históricos são abordadas considerandose o contexto social, cultural, político, econômico e o pensamento crítico da época; logo em seguida, passa-se a fazer uma leitura e interpretação de artefatos culturais, de desconhecidos e de expoentes; e finalmente, o discente é instigado a propor uma reflexão estética, teórica e prática, através do embate entre o momento estudado e o momento que vive, e desenvolver uma poesia visual.

\section{SISTEMA DE AVALIAÇÃO.}

A universidade trabalha com duas grandes notas que são compostas por: N1, quatro avaliações valendo 10 pontos, que podem ser compostas por duas provas sem consulta e outras duas avaliações de livre escolha, assim, são feitas duas provas, valendo duas avaliações N1, 5 trabalhos que são apresentados e avaliados em sala de aula, os quais somados valem por uma avaliação da nota N1, e um trabalho coletivo com peças de diferentes formatos as quais apresentadas valem por uma avaliação da nota N1; e N2, duas 
avaliações que somadas valem 10 pontos, uma prova sem consulta valendo 5 pontos e a nota da avaliação da banca valendo 5 pontos.

\section{CONSIDERAÇÕES FINAIS.}

De acordo com o Projeto Pedagógico do Curso - PPC a disciplina de "Fundamentos do Design" funciona como um laboratório crítico, teórico e prático, que tem a função de proporcionar: a reflexão e a crítica sobre as cadeias de acontecimentos históricos e os fatos históricos narrados; a análise das relações entre as teorias filosóficas e estéticas, os valores socioculturais e econômicos e os momentos tecnológicos, com o intuito de promover a percepção de como os momentos históricos resultam de conjuntura, a qual configura o conjunto de relações que caracterizam cada momento da história do design; o contato, a análise e a interpretação de projetos relevantes de designers, a partir dos próprios artefatos originais; a experimentação e produção de traduções de princípios filosóficos e estéticos em composições plásticas; e por fim, a análise e a discussão sobre a importância do discurso narrativo na construção e na sedimentação da prática da atividade projetual do design voltada ao futuro.

\section{REFERÊNCIAS:}

ALDERSEY-WILLIAMS, Hugh et al. Cranbrook design: the new discourse. New York: Rizzoli International Publications, 1990.

AOUST, Patrice. 100 annees de creation: ecole boulle 1886-1986. Paris: Éditions SytosAlternatives, 1986.

BARDI, Lina Bo. Tempos de grossura: o design no impasse. São Paulo: Instituto Lina Bo e P. M. Bardi, 1994.

BIELINSKI, Alba Carneiro. O Liceu de Artes e Ofícios: sua história de 1856 a 1906. Rio de Janeiro: Revista Dezenove e Vinte, v. IV, no 1, jan. 2009. Disponível em: < http://www.dezenovevinte.net/ensino_artistico/liceu_alba.htm >. Acesso em: 10 mar. 2013.

BUCHANAN, William (Ed.). Mackintosh's masterwork: the Glasgow school of art. New Jersey: Rutgers University Press, 2004.

CARDOSO, Rafael. A Academia Imperial de Belas Artes e o Ensino Técnico. Rio de Janeiro: Revista Dezenove e Vinte, v. III, nº, 1 , jan. 2008. Disponível em: < http://www.dezenovevinte.net/ensino_artistico/rc_ebatecnico.htm >. Acesso em: 10 mar. 2013. 
CIPINIUK, Alberto. A pedagogia de Lebreton. Rio de Janeiro: Revista Dezenove e Vinte, v. I, no 1, mai. 2006. Disponível em: < http://www.dezenovevinte.net/ensino_

artistico/lebreton.htm >. Acesso em: 10 mar. 2013.

DEWEY, John. Arte como experiência. São Paulo: Martins Fontes, 2010.

DEWEY, John. Cultura e indústria na educação. In: BARBOSA, Ana Mae. John Dewey e o ensino da arte no brasil. São Paulo: Cortez Editora, 2011, pg.23-32.

DEWEY, John. Experiência e educação. Petrópolis: Editora Vozes, 2011.

ESPINOZA, Eduardo Castilho (Org.) Artesanatos, artistas, artífices: la escule de artes aplicadas de la universidad de chile 1928-1968. Santiago: Ocho Libros Editores, 2010. FERNÁNDEZ, Silvia; BONSIEPE, Gui (Org.). Historia del deseño en américa latina y el caribe: industrialización y comunicación visual para la autonomia. São Paulo: Blucher, 2008.

FIEDLER, Jeannine (Ed.). Bauhaus. Oxford: Könemann, 2006.

KOVENSKY, Julia; SQUEFF, Leticia (Org.). Araújo Porto-Alegre: singular e plural. São Paulo: IMS, 2014.

LIMA, Raquel Rodrigues. Porto Alegre: jan. 2000. Liceu Parobé: um instituto das artes e ofícios. Disponível em: < http://www.ufrgs.br/propar/publicacoes/ARQtextos/ PDFs_revista_0/0_\%20Raquel.pdf >. Acesso em: 10 mar. 2013.

MAGOMEDOV, S. Khan. Vhutemas 1920-1930. Paris: Edition du Regard, 1990.

NIEMEYER, Lucy. Design no brasil: origens e instalação. Rio de Janeiro, 2AB, 1998.

SIMONDON, Gilbert. La individuación a la luz de las nociones de forma y información. Buenos Aires: Ediciones La Cebra; Editorial Catus, 2009.

SPITZ, René. Hfg ulm: the view behind the foreground: the political history of the ulm school of design - 1953-1968. Stuttgart: Edition Axel Menges, 2002.

TORRENT, Rosalía; MARÍN, Joan M. Historia del desiño industrial. Madrid: Ediciones Cátedra, 2005. 